\title{
PELAKSANAAN MANAJEMEN MUTU PROSES PEMBELAJARAN SEKOLAH MENENGAH ATAS
}

\author{
Hendro Prasetyono ${ }^{1}$, Sumaryati Tjitrosumarto ${ }^{2}$, J. Sabas Setyohadi ${ }^{3}$ \\ ${ }_{1,2,3}$ Universitas Indraprasta PGRI \\ Email: hendro_prasetyono@unindra.ac.id
}

Dikirim: 25 September 2020; Direvisi: 17 Oktober 2020; dipublikasikan: 24 Desember 2020

\begin{abstract}
ABSTRAK
Hasil prestasi belajar siswa sekolah menengah atas negeri di DKI Jakarta masih perlu ditingkatkan. Pelaksanaan mutu proses pembelajaran yang seharusnya dapat meningkatkan kualitas proses pembelajaran perlu dianalisis. Penelitian ini menggunakan pendekatan kualitatif dengan metode grounded research. Teknik pengambilan data menggunakan wawancara, observasi dan studi dokumen. Informan kunci dalam penelitian ini adalah kepala sekolah, wakil kepala sekolah dan guru dari SMA 104 dan 62 Jakarta. Teknik analisis data menggunakan reduksi data, display dan verifikasi. Pelaksanaan mutu proses pembelajaran yang dilaksanakan di SMA 104 dan 62 Jakarta belum maksimal. Hal ini karena ditemukan cukup banyak guru yang belum konsisten melaksanakan kegiatan belajar mengajar menggunakan metode pembelajaran berdasarkan kurikulum yang digunakan sekolah. Guru perlu diikutkan dalam pelatihan penggunaan metode pembelajaran kooperatif. Supervisi kepala sekolah diperlukan lebih intensif untuk dapat melakukan yang lebih optimal.
\end{abstract}

Kata kunci: manajemen mutu, metode pembelajaran, kompetensi pedagogik, grounded research

\begin{abstract}
The learning achievement results of state senior high school students in DKI Jakarta still need to be improved. The implementation of the quality of the learning process which should be able to improve the quality of the learning process needs to be analyzed. This study uses a qualitative approach with grounded research methods. Data collection techniques using interviews, observation and document study. The key informants in this study were principals, deputy principals and teachers from SMA 104 and 62 Jakarta. Data analysis techniques used data reduction, display and verification. The implementation of the quality of the learning process carried out at state senior high school DKI Jakarta has not been optimal. This is because it is found that there are quite a number of teachers who have not consistently implemented teaching and learning activities using learning methods based on the curriculum used by schools. Teachers need to be included in training on the use of cooperative learning methods. Supervision of the principal is needed more intensively to be able to do more optimally.
\end{abstract}

Keywords: quality management, learning methods, pedagogical competence, grounded research 


\section{PENDAHULUAN}

Kualitas sumberdaya manusia Indonesia masih perlu ditingkatkan. Menurut Bank Dunia Indeks Modal Manusia (Human Capital Index/HCI) tahun 2020 mendapat skor 0,54 menempatkan Indonesia para peringkat ke-96 dari 174 negara (Kompas, 2020). Skor tersebut beda tipis dengan tahun 2019, yaitu 0,53 dan posisi Indonesia masih dibawah Vietnam (38), Malaysia (62) dan Thailand (63). Kondisi serupa juga dari posisi Indonesia pada Human Development Indeks (HDI) 2018 berada pada peringkat 111 dari 189 negara dengan skor 0,707 naik sedikit dari tahun sebelumnya 2017 yaitu sebesar 0,704 (UNDP, 2019).

Salah satu kunci permasalahan dalam dunia pendidikan sampai saat ini adalah mutu lulusan yang dipandang oleh para stakeholders belum memuaskan (Hendro Prasetyono, Abdillah, \& Fitria, 2018). Masih tingginya angka pengangguran, prestasi belajar siswa yang belum sesuai dengan harapan dan gap antara kompetensi lulusan dengan kebutuhan dunia industri merupakan sebagian permasalahan yang masih muncul sampai saat ini (H. Prasetyono, Abdillah, Widiarto, \& Sriyono, 2018). Kondisi ini ditambah lagi dengan dunia saat ini memasuki era Revolusi Industri 4.0 yang disinyalir memiliki perubahan 10 (sepuluh) kali lebih cepat dari era sebelumnya memaksa setiap negara dan organisasi berbenah diri dengan baik (Mourtzis, Vlachou, Dimitrakopoulos, \& Zogopoulos, 2018).

Upaya pemerintah dalam meningkatkan mutu pendidikan melalui kebijakan pembangunan pendidikan telah dilakukan seperti perluasan kesempatan belajar, meningkatkan mutu pendidikan, peningkatan relevansi, dan efektivitas penyelenggara pendidikan . Kemudian upaya lain juga telah dilakukan oleh pemerintah untuk meningkatkan mutu pendidikan melalui peningkatan dan pengambangan kemampuan tenaga pendidik seperti pembentukan Musyawarah Guru Mata Pelajaran Sejenis (MGMP), Pusat Kegiatan Guru (PKG), Lembaga Balai Penataran Guru (BPG) dan lainnya.

Berbagai upaya pemerintah untuk meningkatkan mutu pendidikan tersebut sampai saat belum dikatakan berhasil secara signifikan. Hal ini terlihat dari prestasi belajar siswa dalam proses pembelajaran yang masih perlu ditingkatkan. Belum maksimalnya prestasi belajar siswa terlihat dari hasil penyelenggaran Ujian Nasional (UN) pada tahun 2019 yang menunjukkan nilai rata-rata ujian nasional yang belum menunjukkan peningkatan yang signifikan pada jenjang menengah atas secara nasional.

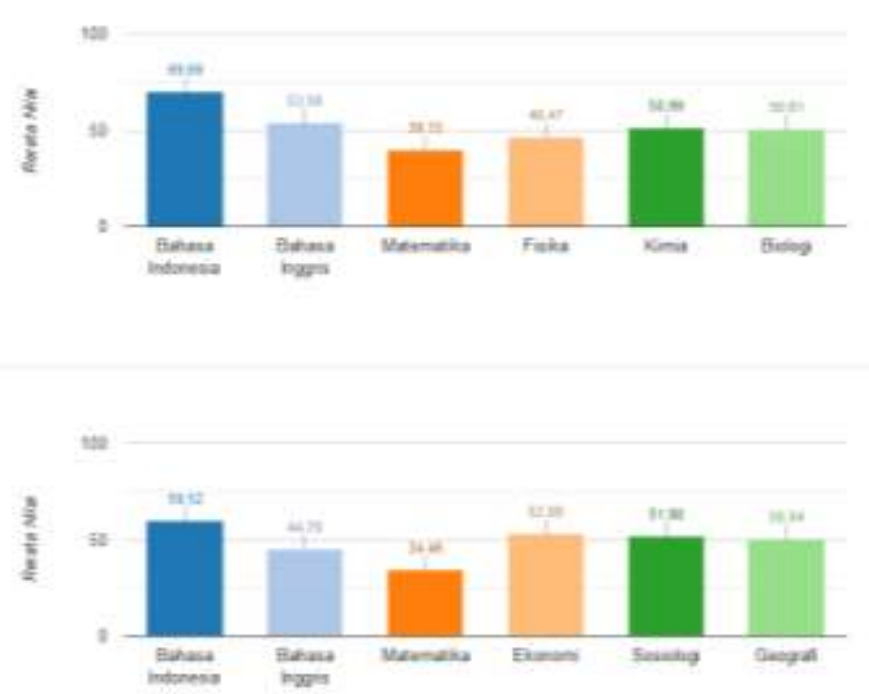

Gambar 1. Hasil Ujian Nasional Tahun 2018/2019 Jenjang SMA (sumber: https://pusmenjar.kemdikbud.go.id/hasilun/) 
Berdasarkan gambar 1 tersebut diketahui jika secara nasional pada jenjang SMA baik program IPA atau IPS nilai rata-rata UN masih rendah. Hampir pada semua mata pelajaran baik pada program IPA maupun IPS berada pada kisaran angka 50. Hal ini berarti dalam hal prestasi belajar siswa masih perlu ditingkatkan. Namun untuk dapat meningkatkan kualitas prestasi belajar agar optimal perlu memperhatikan faktor-faktor yang mempengaruhi prestasi belajar. Hasil penelitian sebelumnya memperlihatkan bahwa prestasi belajar salah satunya sangat dipengaruhi saat proses pembelajaran di sekolah (Ramadhan \& Soenarto, 2015; Setiawati, 2015).

Proses pembelajaran di sekolah yang berkualitas sangat ditentukan oleh kompetensi pedagogik guru (Pujiastuti, Raharjo, \& Widodo, 2012). Kompetensi guru merupakan kemampuan guru dalam melaksanakan berbagai kewajiban secara bertanggung jawab dan layak (Doležalová, 2015). Jadi kemampuan ini meliputi kewenangan guru dalam menjalankan profesi keguruannya. Secara umum kompetensi guru terdiri atas kompetensi pedagogik, kompetensi kepribadian, kompetensi sosial dan kompetensi profesional (Fahdini, Mulyadi, Suhandani, \& Julia, 2014). Diantara empat kompetensi tersebut yang paling mempengaruhi hasil pembelajaran adalah kompetensi pedagogik (Umami \& Roesminingsih, 2014).

Kompetensi pedagogik guru adalah kemampuan mengelola pembelajaran peserta didik yang meliputi pemahaman terhadap peserta didik, perancangan dan pelaksanaan pembelajaran, evaluasi hasil belajar dan pengembangan peserta didik untuk mengaktualisasikan berbagai potensi yang dimilikinya (Umami \& Roesminingsih, 2014). Pengertian tersebut menjelaskan bahwa kompetensi pedagogik guru merupakan kemampuan seorang guru didalam mengelola atau mengatur pembelajaran yang diajarkan kepada peserta didik. Sedangkan dalam proses pembelajaran di kelas kompetensi pedagogik guru terlihat dari kemampuan guru dalam menjelaskan materi, melaksanakan metode pembelajaran, memberikan pertanyaan, menjawab pertanyaan, mengelola kelas, dan melakukan evaluasi, (Muchith, 2008:148).

Secara rinci dalam Permendiknas No 16 tahun 2007, kompetensi pedagogik dijabarkan menjadi indikator esensial sebagai berikut: (1) Menguasai karakteristik peserta didik dari aspek fisik, moral, sosial, cultural, emosional dan intelektual; (2) Menguasai teori beiajar dan prinsipprinsip pembelajaran yang mendidik; (3) Mengembangkan kurikulum yang terkait dengan bidang pengembangan yang diampu; (4) Menyelenggarakan kegiatan pengembangan yang mendidik; (5) Memanfaatkan teknologi informasi dan komunikasi untuk kepentingan penyelenggaraan pengembangan yang mendidik; (6) Memfasilitasi pengembangan potensi peserta didik untuk mengaktualisasikan berbagai potensi yang dimiliki; (7) Berkomunikasi secara efektif, empatik dan santun dengan-peserta didik; (8) Menyelenggarakan penilaian dan evaluasi hasil belajar; (9) Memanfaatkan hasil penilaian dan evaluasi untuk kepentingan pembelajaran; (10) Melakukan tindakan reflektif untuk peningkatan kualitas pembelajaran

Salah satu cara yang bisa dilakukan untuk meningkatkan kompetensi pedagogik guru adalah pelaksanaan manajemen mutu pembinaan kompetensi pedagogik guru yang perlu dioptimalkan (Suharini, 2009). Hasil penelitian mengungkapkan bahwa sekolah yang memiliki program pembinaan kompetensi guru yang bermutu akan menghasilkan lulusan yang lebih berkualitas dibandingkan dengan sekolah yang belum menerapkan pembinaan kompetensi guru (Kim, Xie, \& Cheng, 2017). Temuan ini sangatlah wajar karena guru merupakan ujung tombak dalam keberhasilan suatu program pendidikan sehingga pembinaan kompetensi guru harus dilakukan secara bermutu.

Perbaikian secara terus menerus atau yang dikenal dengan istilah Manajemen Mutu Terpadu (MMT) merupakan salah satu solusi yang bisa dimaksimalkan untuk mengatasi hal ini. MMT merupakan filosofi atau metodologi pengelolaan institusi secara terus menerus untuk mencapai kepuasan pelanggan saat ini maupun masa datang (Antony \& Preece, 2002). Pengelolaan lembaga pendidikan melalui manajemen yang baik sangat penting dilakukan untuk menghasilkan mutu lulusan sesuai dengan harapan para orang tua, stakeholders maupun tujuan 
dari pendidikan nasional itu sendiri. Oleh karena itu, mutu menjadi agenda utama dan tugas utama bagi setiap lembaga agar berkembang dan dapat meraih status di tengah-tengah persaingan global.

Manajemen mutu terpadu lembaga pendidikan sebagai industri jasa memberikan pelayanan sesuai dengan apa yang diinginkan oleh pelanggan (Sallis, 2005). Jasa atau pelayanan yang diinginkan oleh pelanggan tentunya layanan yang bermutu sehingga dapat memberikan kepuasan. Oleh karena itu lembaga pendidikan perlu untuk memposisikan diri sebagai lembaga pendidikan yang memberikan jasa bermutu dengan cara memenuhi standar mutu tersebut sesuai spesifikasi mutu yang telah ditetapkan. Standar mutu adalah mutu sesungguhnya, persepsi mutu, mutu tanpa cacat dan selalu baik sejak awal (Sallis, 2005). Konsep mutu dalam pendidikan harus sesuai standar nasional pendidikan, dan mutu persepsi diukur dari kepuasan pelanggan atau pengguna, meningkatkan minat, harapan dan kepuasan pelanggan (D.Mauch, 2010).

Pelaksanaan mutu terdiri atas indikator model pelaksanaan mutu, dimensi pelaksanaan mutu dan fase pelaksanaan mutu (Anastasiadou, 2015). Model pelaksanaan mutu terkait dengan pilihan metode yang digunakan oleh sekolah dalam implementasi kebijakan mutu. Dimensi pelaksanaan mutu merupakan indicator-indikator dari mutu yang harus diimplementasikan dan gunakan dalam pelaksanaan mutu yang disusun berdasarkan budaya dan tujuan sekolah. Fase pelaksanaan mutu merupakan tahapan atau posisi ketercapaian mutu dalam implementasi yang digunakan.

Kinerja guru pada jenjang menengah atas di DKI Jakarta masih perlu ditingkatkan. Hal ini terlihat dari data nilai UN baik pada program IPA maupun IPS yang masih rendah.

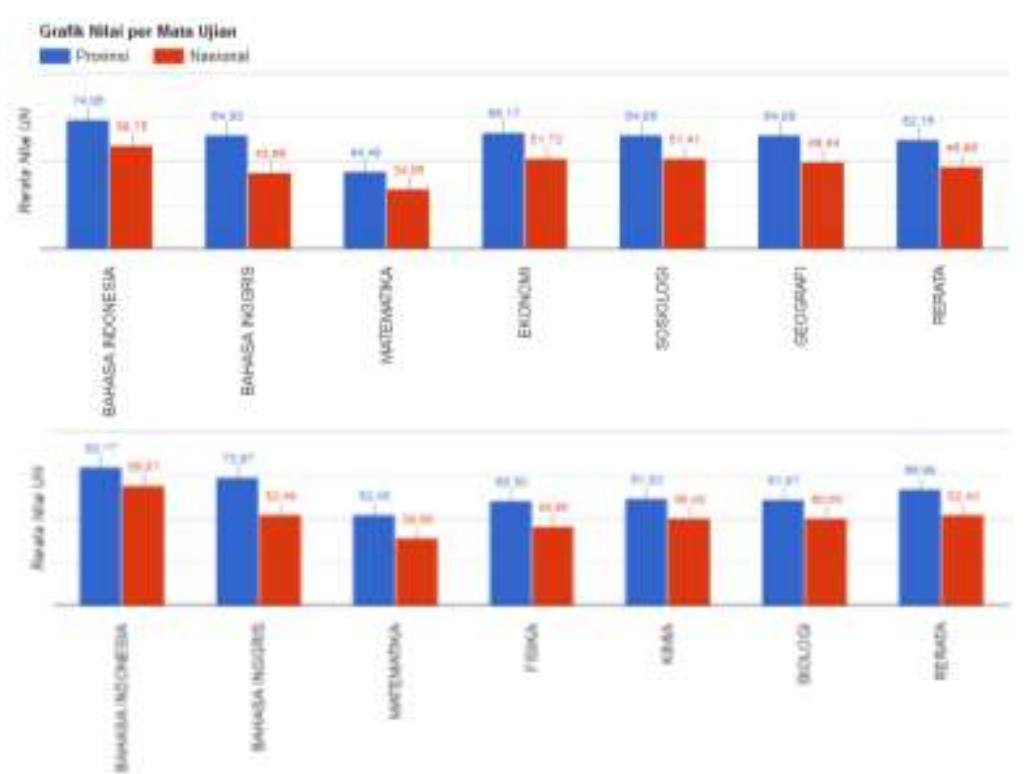

Gambar 2. Rata-rata nilai UN 2018/2019 Jenjang SMA di DKI Jakarta

(sumber: https://pusmenjar.kemdikbud.go.id/hasilun/)

Berdasarkan grafik tersebut diketahui bahwa meskipun Provinsi DKI Jakarta memiliki prestasi nilai UN yang lebih tinggi rata-rata nilainya jika dibandingkan dengan rata-rata nilai nilai nasional akan tetapi tergolong rendah. Jika diklasifikan menjadi SMA negeri dan swasta ternyata SMA negeri masih dibawah SMA swasta. Menurut data diketahui pada tahun ajaran 2018/2019 SMAN 8 berada pada posisi nomor 10 SMA tertinggi nilai UN nya. Sisanya nomor 1 sampai dengan nomor 9 diduduki oleh SMA swasta (https://pusmenjar.kemdikbud.go.id/hasilun/). 
Hal ini menjadi menarik untuk dikaji karena seharusnya SMA negeri yang memang dipersiapkan untuk seluruh anak bangsa akan tetapi hasil kualitas nilai UN masih kalah dari SMA swasta yang hanya bisa dinikmati oleh kalangan atas. Oleh karena itu perlu dilakukan kajian empiris secara mendalam pelaksanaan manajemen mutu proses pembelajaran SMA di DKI Jakarta.

\section{METODE}

Penelitian dilaksanakan pada 2 SMAN di Jakarta, yaitu SMAN 104 dan SMA 62 dengan pertimbangan telah menerapkan standar ISO 9001:2008. Penerapan standar ISO membuktikan bahwa sekolah tersebut telah menerapkan standar mutu manajemen tata laksana yang salah satunya meliputi kompetensi pedagogik guru. Penelitian dilaksanakan pada Bulan September 2019 sampai dengan Januari 2020. Pendekatan penelitian adalah kualitatif dengan metode grounded theory. Grounded thory dipilih karena paling sesuai untuk menggali informasi atau fakta terkait dengan suatu fenomena terjadi untuk dijadikan suatu teori baru (Stake, 2010). Langkah-langkah dalam grounded theory adalah a. Menentukan masalah yang diteliti; b. Mengumpulkan data yang dibutuhkan; c. Menganalisis dan menjelaskan data yang terkumpul. d. Membuat laporan penelitian (Strauss \& Corbin, 1998).

Informan kunci dalam penelitian ini adalah kepala sekolah, wakil kepala sekolah dan guru. Focus penelitian ini adalah mendeskripsikan pelaksanaan manajemen mutu proses pembelajaran dengan sub focus pada model pelaksanaan, dimensi pelaksanaan dan fase pelaksanaan mutu. Teknik pengumpulan data menggunakan wawancara mendalam, obervasi dan studi dokumen yang ditentukan dengan tabel berikut:

Tabel 1. Teknik Pengambilan Data

\begin{tabular}{ccccc}
\hline No & Subfokus Penelitian & \multicolumn{3}{c}{ Pengambilan Data } \\
& & Wawancara & Studi Dokumen & Observasi \\
\hline 1 & Model pelaksanaan mutu & $\sqrt{ }$ & $\sqrt{ }$ & \\
2 & Dimensi pelaksanaan mutu & $\sqrt{ }$ & $\sqrt{ }$ & $\sqrt{ }$ \\
3 & Fase pelaksanaan mutu & $\sqrt{ }$ & & \\
\hline
\end{tabular}

Teknik analisis data menggunakan reduksi, display dan verikasi data (Matthew B. Miles \& Huberman, 1994). Pada tahap reduksi dan display data menggunakan coding dan open coding untuk pengelompokkan untuk kemudian ditarik kesimpulan. Tahap reduksi adalah data yang telah dikumpulkan dari berbagai teknik pengambilan data disusun dengan menghilangkan bagian yang tidak sesuai dengan focus penelitian. Tahap display data merupakan tahap peneliti akan membadingkan data hasil wawancara dengan temuan hasil studi dokumen atau observasi terhadap terkait dengan subfokus. Tahap verifikasi merupakan tahap menafsirkan hasil display data yang kemudian dikaji dengan teori atau penelitian terdahulu (Singh, 2007).

\section{HASIL DAN PEMBAHASAN \\ Hasil}

Masalah dalam penelitian ini adalah prestasi belajar siswa SMAN di Jakarta yang tertinggal dengan SMA swasta yang berdasarkan hasil grand tour studi pendahuluan salah satu disebabkan karena mutu proses pembelajaran. Perlu dianalisis pelaksanaan mutu proses pembelajaran guru SMA 62 dan 104 di DKI Jakarta dengan subfokus pada model pelaksanaan, dimensi pelaksanaan dan fase pelaksanaan mutu.

Berdasarkan hasil wawancara terhadap 6 orang informan kunci untuk sub focus model pelaksanaan mutu tahap reduksi data tersaji pada tabel berikut: 
Volume 12, No. 3, Desember 2020, pp. 243-252

e-ISSN: $2502-5449$

p-ISSN: 2085-2266

DOI : $10.30998 /$ sosioekons.v12i3.7626

Tabel 2. Hasil Wawancara Model Pelaksanaan Mutu

\begin{tabular}{lll}
\hline SMA 104 & \multicolumn{2}{c}{ SMA 62 } \\
\hline Model pelaksanaan mutu pembelajaran & Model yang lain, misalnya Model \\
ekonomi di sekolah mengacu pada prestasi dan & Pembelajaran Kooperatif: Orientasi, \\
mutu sekolah. Landasan pemilihan model & Eksplorasi, Pendalaman, Kesimpulan. \\
pelaksanaan mutu pembelajaran ekonomi di & Landasan pemilihan model pelaksanaan \\
sekolah adalah peningkatan prestasi presstasi & mutu pembelajaran ekonomi kelas X di \\
pada jenjang akademik dan non akademik. & sekolah berdasarkan Karakteristik \\
Model pelaksanaan mutu di sekolah adalah & materi, Daya dukung SDM, Sarana, \\
PDCA (Plan, Do, Check, Action), POAC & Waktu yang tersedia. Yang menjadi \\
(planning, organizing, actuating, controlling). & landasan pemilihan model pelaksanaan \\
Sekolah melakukan upaya perbaikan atau & mutu pembelajaran ekonomi adalah \\
penyempurnaan secara terus menerus atau & keadaan siswa, daya dukung sekolah dan \\
tahun ajaran & kesempatan \\
\hline
\end{tabular}

Tabel 3. Hasil Wawancara Dimensi Pelaksanaan Mutu

\begin{tabular}{|c|c|}
\hline SMA 104 & SMA 62 \\
\hline $\begin{array}{l}\text { Indikator dalam keberhasilan } \\
\text { pelaksanaan mutu pembelajaran } \\
\text { ekonomi di sekolah adalah } \\
\text { kompetensi guru, sertifikat guru, } \\
\text { pencapaian prestasi siswa dengan } \\
\text { UN atau diterima di PTS, buku } \\
\text { acuan pembelajaran. }\end{array}$ & $\begin{array}{l}\text { Komponen pelaksanaan mutu pembelajaran ekonomi } \\
\text { kelas X di sekolah adalah Guru melaksanakan } \\
\text { kegiatan sesuai fungsinya sebagai lembaga } \\
\text { pendidikan; Guru dan sekolah memiliki nilai } \\
\text { kelebihan atau keunggulan; Tingkat kepercayaan } \\
\text { guru dan sekolah yang baik, yang menghasilkan } \\
\text { tamatan bermutu; Fasilitas KBM memenuhi standar; } \\
\text { Budaya dan kondisi pengelolalaan kelas nyaman } \\
\text { serta menyenangkan, RPP minimal } 75 \% \text { terlaksana } \\
\text { dan ketercapaian KKM secara kognitif, afektif dan } \\
\text { psikomotor tercapai }\end{array}$ \\
\hline
\end{tabular}

Tabel 4. Hasil Wawancara Fase Pelaksanaan Mutu

SMA $104 \quad$ SMA 62

\begin{tabular}{ll}
\hline Pelaksanaan mutu di sekolah adalah & Pada semua tahapan atau peringkat, karena dalam \\
pada fase pelaksanaan. Hambatan & KBM tahapan nya tidak harus urut, dan tidak harus \\
dalam pelaksanaan mutu di sekolah & semua dilaksanakan bersamaan atau sekaligus. \\
adalah rendahnya nilai Nilai EBTA & Dilaksanakan yang paling sesuai dengan karakter \\
Murni yang diperoleh dari Sekolah & ilmu dan kondisi sekolah dan peserta didik. \\
Lanjutan Tingkat Pertama, dan & Hambatan dalam pelaksanaan mutu pembelajaran \\
Proses mutu yang dilalui selama & siswa yang cenderung menggunakan HP di kelas \\
belajar di SMA & untuk hal diluar proses pembelajaran dan perubahan \\
& kurikulum serta sarpras lab IPS kurang \\
\hline
\end{tabular}

Model pelaksanaan mutu berdasarkan hasil studi dokumen merujuk kepada kurikulum yang digunakan oleh sekolah dan pedoman penarapan ISO di sekolah. Hasil studi dokumen kurikulum di sekolah menggunakan 2 kurikulum, yaitu KTSP dan Kurikulum 2013. Masingmasing memiliki ciri yang berbeda. KTSP menggunakan model pembelajaran masteri learning sebagai model pelaksanaan mutu. Sedangkan kurikulum 2013 menggunakan saintifik learning sebagai model pelaksanaan mutu. Hal ini berimbas kepada proses pembelajaran. KTSP menekankan kepada pengajaran sebagai guru di kelas, sedangkan kurikulum 2013 menekankan pada keaktifan siswa dalam mencari pengetahuan. 


\section{sosio e-kons}

Volume 12, No. 3, Desember 2020, pp. 243-252

e-ISSN: $2502-5449$

p-ISSN: 2085-2266

DOI : $10.30998 /$ sosioekons.v12i3.7626

Dimensi pelaksanaan mutu berdasarkan hasil studi dokumen merujuk kepada profil dan latar belakang guru di sekolah. Berdasarkan data sekolah memperlihatkan 82\% guru telah lulus jenjang sarjana (S1) dan 18\% guru telah lulus magister (S2). Namun dari data pembinaan guru baru $54 \%$ guru yang rutin mengikuti seminar atau pelatihan peningkatan kompetensi guru dan mayoritas adalah guru yang telah sertifikasi.

Fase pelaksanaan mutu berdasarkan hasil observasi tidak terlihat secara jelas. Setiap guru dalam melakukan proses pembelajaran dibeberapa kelas menggunakan metode pembelajaran yang berbeda-beda. Masih ada guru yang menggunakan metode konvensional (ceramah), metode diskusi dan tanya jawab, jigsaw dan presentasi dengan minim sekali arahan dari para guru. Jadi belum ada keseragaman antar guru, baik guru yang mengajar mata pelajaran yang sama maupun berbeda.

\section{Pembahasan}

Pembahasan merupakan tahap display dan verfikasi (penarikan kesimpulan) yang dikaji dengan hasil penelitian terdahulu sebagai analisis data.

Model pelaksanaan mutu berdasarkan hasil wawancara adalah menggunakan PDCA dan pembelajaran kooperatif. Pendekatan ini dipilih karena pendekatan proses pembelajaran dilaksanakan oleh setiap unit yang saling terkait satu sama lain dan menjadi laporan yang utuh dalam satuan pendidikan. Namun dalam implementasinya mengikuti pada kondisi peserta didik dan sarana prasarana yang ada. Model pelaksanaan mutu berdasarkan hasil studi dokumen memperlihatkan penggunaan 2 model pembelajaran yang berbeda sebagai akibat dari penggunaan 2 kurikulum yang berbeda. Landasan pemilihan model pelaksanaan mutu pembelajaran ekonomi di sekolah adalah karakteristik materi, daya dukung sumberdaya manusia, sarana dan prasarana serta waktu yang tersedia. Model pelaksanaan mutu adalah siswa belajar dengan nyaman aktif, kreatif, menyenangkan. Model ini dipilih karena keadaan siswa, daya dukung sekolah dan kesempatan.

Penggunaan PDCA pada sekolah merupakan salah satu bagian dari implementasi mutu di sekolah (Bank, 2007). Namun disini guru sebagai eksekutor mutu di kelas juga selaku pengawas mutu. Hal ini akan menimbulkan bias karena jika guru menjadi pelaksana mutu pembelajaran di kelas maka yang menjadi pengawas atau penilai jangan guru itu sendiri (Cahyana, 2010). Bisa oleh wakil kepala sekolah atau guru senior yang ditugaskan sebagai supervisi. Hal ini mutlak diperlukan agar pelaksanaan mutu harus benar-benar terlaksana dengan baik.

Penggunaan metode kooperatif mencirikan bahwa guru tersebut telah mengikuti implementasi kurikulum 2013 (Maba \& Mantra, 2018). Guru akan menggunakan jenis dari metode kooperatif seperti Jigsaw atau STAD yang seluruhnya akan meningkatkan keingintahuan dan kreativitas siswa. Namun guru yang masih menggunakan metode ceramah atau presentasi hampir dipastikan belum mengimplementasikan pengajaran berbasis mutu yang sesuai dengan pedoman kurikulum 2013 (Alawiyah, 2014). Bisa jadi sang guru tersebut enggan atau tidak siap atau tidak memahami metode pembelajaran kooperatif yang menenkankan peserta didik sebagai sumber belajar (Machali, 2014). Berbagai literatur memperlihatkan bahwa mayoritas guru enggan untuk mempelajari atau menggunakan metode kooperatif karena kesulitan dalam mengadopsi dalam proses mengajar sehari-hari (Natsir, Qismullah Yusuf, \& Fiolina Nasution, 2018). Jika hal ini tidak diperbaiki maka mutu pembelajaran sulit untuk mengalami peningkatan kualitas.

Dimensi pelaksaan mutu berdasarkan hasil wawancara sangat tergantung kepada kualifikasi pendidikan, sertifikasi guru, buku ajar dan sarana prasarana di sekolah. Indikator keberhasilan pelaksanaan mutu adalah apa yang direncanakan dalam RPP minimal $75 \%$ terlaksana untuk aspek kognitif, afektif dan psikomotor tercapai. Komponen pelaksanaan mutu meliputi manajemen sekolah, guru, sarpras, siswa, orang tua, masyarakat dengan indikator pelayanan pendidikan, hasil belajar, out put, out come dengan tahapan dalam proses 


\section{sosio e-kons}

Volume 12, No. 3, Desember 2020, pp. 243-252

e-ISSN: $2502-5449$

p-ISSN: 2085-2266

DOI : $10.30998 /$ sosioekons.v12i3.7626

pembelajaran, yaitu mengamati, menanya, mengumpulkan, informasi, mengasosiasi, dan mengkomunikasikan. Dimensi pelaksanaan mutu berpatokan kepada guru melaksanakan kegiatan sesuai fungsinya sebagai lembaga pendidikan; guru dan sekolah memiliki nilai kelebihan atau keunggulan; tingkat Kerpercaya guru dansekolah yang baik, yang menghasilkan tamatan bermutu; fasilitas KBM memenuhi standar; budaya dan kondisi pengelolalaan kelas nyaman serta menyenangkan.

Temuan tersebut menunjukkan sekolah belum sepenuhnya melaksanakan dimensi pelaksanaan mutu pendidikan dengan tepat. Menurut Darmaji, Supriyanto, \& Timan, (2019 dan Fadhli (2017) dimensi mutu pelaksanaan pengajaran meliputi kualifikasi pendidikan, sarana dan prasarana, metode pembelajaran dan evaluasi. Masih perlu dilakukan penekanan bahwa penggunaan metode pembelajaran yang tepat dan sesuai dengan ciri khas mata pelajaran penting untuk meningkatkan pemahaman siswa dalam belajar (Buhr, Heflin, White, \& Pinheiro, 2014). Siswa akan lebih nyaman, mudah dalam menyerap materi dan termotivasi karena guru dan metode pembelajaran yang sesuai.

Fase pelaksanaan mutu berdasarkan hasil wawancara baru kepada fase awal pelaksanaan mutu. Hal ini terlihat dari pernyataan responden fasilitas yang masih perlu ditambah dan proses pengimplementasinya menyesuaikan pada kondisi siswa. Sekolah ini berada pada semua fase, karena dalam KBM tahapan nya tidak harus urut, dan tidak harus semua dilaksankan bersamaan atau sekaligus. Dilaksanakan yang paling sesuai dengan karakter ilmu dan kondisi sekolahdan peserta didik.

Fase pelaksanaan mutu berarti merupakan fase yang masih sangat rentan untuk goyah atau terguncang dalam proses pengimplementasian mutu (Hendartho, 2014). Fase awal ini membutuhkan dukungan dan partisipasi dari beragam pihak agar bisa kokoh dan tumbuh kuat. Setiap individu di sekolah masih belum paham betul atau merasa bahwa mutu pembelajaran sangat penting untuk dijaga dan diimplementasikan. Jika guru dalam penggunaan metode mengajar belum seragam, pemahaman konsep materi yang diberikan oleh siswa belum seragam pula dan belum melakukan tindakan nyata untuk meningkatkan kualitas dirinya maka akan sulit untuk meningkatkan pembelajaran yang bermutu (Şengül \& Katranci, 2014).

\section{SIMPULAN}

Hasil UN SMA yang masih belum menggembiarakan pada SMAN 62 dan 104 salah satunya disebabkan karena pelaksanaan manajemen mutu proses pembelajaran belum maksimal. Masih cukup banyak ditemukan guru yang belum konsisten melaksanakan kegiatan belajar mengajar menggunakan metode pembelajaran berdasarkan kurikulum yang digunakan sekolah. Masih perlu didalami penyebab hal ini karena seharusnya guru perlu selalu meningkatkan kompetensi pedagogik untuk dapat mengajar dengan baik. Bedasarkan hal tersebut dapat disusun suatu teori bahwa keberhasilan pelaksanaan manajemen mutu proses pembelajaran di SMA salah satunya ditentukan oleh konsistensi penggunaan matede pembelajaran yang sesuai dengan kurikulum yang digunakan.

\section{SARAN}

Ketidakonsistenan yang terjadi dapat disebabkan oleh kompetensi pedagogik guru yang perlu ditingkatkan. Oleh karena itu perlu dilakukan pelatihan-pelatihan penggunaan metode pembelajaran yang lebih beragam. Kepala sekolah harus lebih konsisten dalam melakukan supervisI agar dapat benar-benar diketahui guru yang benar-benar membutuhkan pembinaan dari kepala sekolah. 


\section{DAFTAR RUJUKAN}

Alawiyah, F. (2014). Kesiapan guru dalam implementasi kurikulum 2013. Kajian Singkat, VI (15), 9-11.

Anastasiadou, S. D. (2015). The Roadmaps of Total Quality Management in the Greek Education System According to Deming, Juran, and Crosby in light of the EFQM Model. Procedia Economics and Finance, 33(15), 562-572. https://doi.org/10.1016/s22125671(15) 01738-4

Antony, J., \& Preece, D. (2002). Understanding, Managing and Implementing Quality Frameworks, techniques and cases. London: Routledge.

Bank, T. W. (2007). Toward High-quality Education in Peru (Standards, Accountability, and Capacity Building). Retrieved from http://search.ebscohost.com/login.aspx?direct=true\&AuthType=ip,url,cookie,uid\&db=ecn $\& \mathrm{AN}=0961015 \&$ site $=$ ehost-live $\&$ scope $=$ site

Buhr, G. T., Heflin, M. T., White, H. K., \& Pinheiro, S. O. (2014). Using the Jigsaw cooperative learning method to teach medical students about long-term and postacute care. Journal of the American Medical Directors Association, 15(6), 429-434. https://doi.org/10.1016/j.jamda.2014.01.015

Cahyana, A. (2010). Upaya Peningkatan Mutu Sekolah Melalui Otonomi Satuan Pendidikan. Jurnal Pendidikan Dan Kebudayaan, 16(2), 109-117.

D.Mauch, P. (2010). Quality Management:theory and application.

Darmaji, Supriyanto, A., \& Timan, A. (2019). Sistem Penjaminan Mutu Internal Sekolah Untuk Meningkatkan Mutu Lulusan. JMSP (Jurnal Manajemen Dan Supervisi Pendidikan), 3(3), 130-137.

Doležalová, J. (2015). Competencies of Teachers and Student Teachers for the Development of Reading Literacy. Procedia - Social and Behavioral Sciences, 171, 519-525. https://doi.org/10.1016/j.sbspro.2015.01.156

Fadhli, M. (2017). Manajemen Peningkatan Mutu Pendidikan. TADBIR (Jurnal Studi Manajemen Pendidikan)2, 1(02), 215-240.

Fahdini, R., Mulyadi, E., Suhandani, D., \& Julia. (2014). Identifikasi Kompetensi Guru Sebagai Cerminan Profesionalisme Tenaga Pendidik Di Kabupaten Sumedang (Kajian Pada Kompetensi Pedagogik). Mimbar Sekolah Dasar, 1(2), 33-42. https://doi.org/10.17509/mimbar-sd.v1i2.874

Hendartho, D. (2014). Analisis Implementasi Sistem Manajemen Mutu ISO 9001:2008 Pada Sekolah Tinggi Ilmu Administrasi Mandala Indonesia. TRANSPARANSI (Jurnal Ilmu Administrasi), VI(2), 124-138.

Kim, M. K., Xie, K., \& Cheng, S. L. (2017). Building teacher competency for digital content evaluation. Teaching and Teacher Education, 66, 309-324. https://doi.org/10.1016/j.tate.2017.05.006

Kompas. (2020, September). Modal Manusia Rendah Hambat Pemulihan. Kompas, p. 10.

Maba, W., \& Mantra, I. B. N. (2018). The Primary School Teachers' Competence in Implementing The 2013 Curriculum. SHS Web of Conferences, 42(35), 1-7. https://doi.org/10.1051/shsconf/20184200035

Machali, I. (2014). Kebijakan perubahan kurikulum 2013 dalam menyongsong indonesia emas tahun 2045. Jurnal Pendidikan Islam, 3(1), 71-94. https://doi.org/10.14421/jpi.2014.31.71-94

Matthew B. Miles, A., \& Huberman, M. (1994). Qualitative Data Analysis: An Expanded Sourcebook (2nd ed.). California: SAGE Publications, Inc.

Mourtzis, D., Vlachou, E., Dimitrakopoulos, G., \& Zogopoulos, V. (2018). Cyber- Physical Systems and Education 4.0 -The Teaching Factory 4.0 Concept. Procedia Manufacturing, 
23(2017), 129-134. https://doi.org/10.1016/j.promfg.2018.04.005

Natsir, Y., Qismullah Yusuf, Y., \& Fiolina Nasution, U. (2018). The Rise and Fall of Curriculum 2013: Insights on the Attitude Assessment from Practicing Teachers. SHS Web of Conferences, 42, 00010. https://doi.org/10.1051/shsconf/20184200010

Prasetyono, H., Abdillah, A., Widiarto, T., \& Sriyono, H. (2018). Character-based Economic Learning Implementation and Teacher's Reinforcement on Student's Affective Competence in Minimizing Hoax. Cakrawala Pendidikan, 37(3), 426-435.

Prasetyono, Hendro, Abdillah, A., \& Fitria, D. (2018). Academic Supervision toward Teacher ' s Performance through Motivation as Intervening Variable. Journal of Education and Learning (EduLearn), 12(2), 188-197. https://doi.org/10.11591/edulearn.v12i2.7324

Pujiastuti, E., Raharjo, T. J., \& Widodo, A. T. (2012). Kompetensi Profesional, Pedagogik Guru Ipa, Persepsi Siswa Tentang Proses Pembelajaran, Dan Kontribusinya Terhadap Hasil Belajar Ipa Di Smp/Mts Kota Banjarbaru. Innovative Journal of Curriculum and Educational Technology, 1(1), 22-29. Retrieved from http://journal.unnes.ac.id/sju/index.php/ujet

Ramadhan, A. N., \& Soenarto. (2015). Pengaruh Persepsi Siswa Terhadap Faktor-Faktor Yang Mempengaruhi Prestasi Belajar Teori Kejuruan Siswa SMK. Jurnal Pendidikan Vokasi, 5(3), 297-312.

Sallis, E. (2005). Total Quality Management in Education. https://doi.org/10.3126/av.v1i0.5314

Şengül, S., \& Katranci, Y. (2014). Effects of Jigsaw Technique on Mathematics Self-Efficacy Perceptions of Seventh Grade Primary School Students. Procedia - Social and Behavioral Sciences, 116(2006), 333-338. https://doi.org/10.1016/j.sbspro.2014.01.217

Setiawati, L. (2015). Faktor-Faktor Yang Mempengaruhi Prestasi Belajar Praktik Kejuruan Siswa SMK Program Studi Keahlian Teknik Komputer Dan Informatika. Jurnal Pendidikan Vokasi, 5(3), 325-339.

Singh, K. (2007). Quantitative Social Research Methods. Los Angeles: SAGE Publications.

Stake, R. E. (2010). Qualitative Research: Studying How Things Work. New York: The Guilford Press.

Strauss, A., \& Corbin, J. M. (1998). Basics of Qualitative Research : Techniques and Procedures for Developing Grounded Theory. In SAGE Publications. https://doi.org/10.1177/1350507600314007

Suharini, E. (2009). Studi Tentang Kompetensi Pedagogik Dan Profesional Bagi Guru Geografi Di SMA Negeri Kabupaten Pati. Jurnal Geografi, 6(2), 133-145.

Umami, D. R., \& Roesminingsih, E. (2014). Pengaruh Kompetensi Pedagogik dan Motivasi Kerja Guru Terhadap Prestasi Belajar Siswa dalam Ujian Nasional (UN) di SMA Negeri Se Kota Mojokerto. Jurnal Inspirasi Manajemen Pendidikan, 3(3), 81-88.

UNDP. (2019). Briefing note for countries on the 2019 Human Development Report: Indonesia. In Human Development Report 2019: Inequalities in Human Development in the 21st Century. Retrieved from http://hdr.undp.org/sites/all/themes/hdr_theme/countrynotes/NZL.pdf 